\title{
Climate breakdown has passed the point of no return
}

\author{
Minh-Hoang Nguyen \\ Ritsumeikan Asia Pacific University \\ Beppu, Oita 874-8577, Japan
}

August 11, 2021

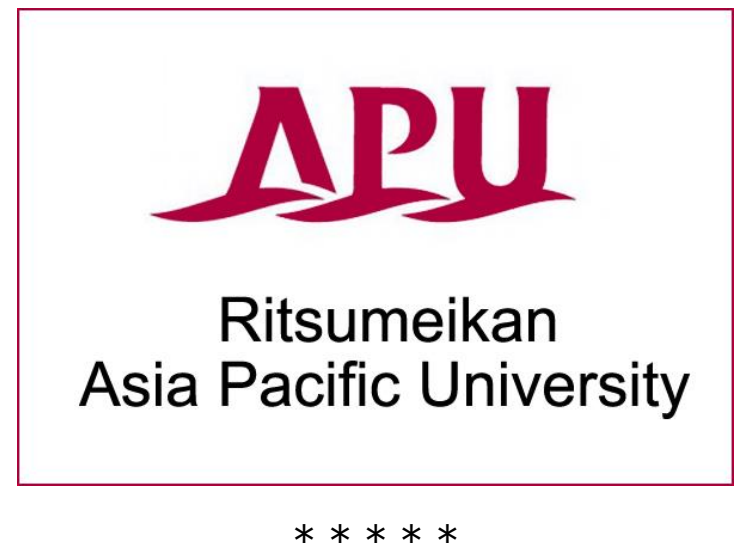

On August 9, 2021, Tollefson reported in Nature [1] that "landmark assessment says that greenhouse gases are unequivocally driving extreme weather - but that nations can still prevent the worst impacts," citing the IPCC report released recently [2].

That means the much-debated climate breakdown has now passed the point of no return, and Tollefson's report calls it "irreversible changes" leading to "extreme impacts".

[...] Oceans are heating up at a pace not seen since the end of the most recent ice age, 11,000 years ago.

Although the report indicates that many of the direst effects of climate change can still be avoided if aggressive action is taken now and that the future is in our hands, the role of the corporate sector in this battle is still unclear. And this is dangerous, according to the study [3].

With the new principle stipulated in [4], we now realize that the fight against climate breakdown is not unconditional. It will have to involve the almighty corporate sector worldwide and be based on the so-called "semiconducting principle of monetary and environmental values exchange."

As a researcher dealing with different aspects of climate change, biodiversity, and ecological resources, I must admit that humankind has little choice but to embrace that important principle and activate the public-private partnership in protecting the environment, and hence human habitats before it becomes too little too late. 


\section{References}

[1] Tollefson J. (2021). IPCC climate report: Earth is warmer than it's been in 125,000 years. Nature, 596, 171-172. doi: 10.1038/d41586-021-02179-1

[2] IPCC. (2021). Climate Change 2021: The Physical Science Basis. https://www.ipcc.ch/report/sixth-assessment-report-working-group-i/

[3] Vuong QH, et al. (2021). Identifying the moral-practical gaps in corporate social responsibility missions of Vietnamese firms: an event-based analysis of sustainability feasibility. Corporate Social Responsibility and Environmental Management, 28(1), 30-41.

[4] Vuong QH. (2021). The semiconducting principle of monetary and environmental values exchange. Economics and Business Letters, 9 (3), 284-290. doi:10.17811/ebl.10.3.2021.284-290 